\title{
Los manglares de Colombia y la recuperación de sus áreas degradadas: revisión bibliográfica y nuevas experiencias
}

\author{
Ricardo Álvarez-León ${ }^{1}$
}

\begin{abstract}
RESUMEN
Se revisa el estado actual de los rodales de manglar y las experiencias silviculturales logradas en las costas colombianas con las especies presentes en el Caribe (Avicennia germinans, Conocarpus erectus, Laguncularia racemosa, Pelliciera rhizophorae y Rhizophora mangle) y las especies del Pacífico (A. germinans, $P$. rhizophorae, $R$. spp.). La mayoría de la información existente corresponde al conocimiento del mangle rojo ( $R$. mangle), lo que en parte se debe a su mecanismo de propagación. Le siguen en orden descendente: $C$. erectus que se usa masivamente en ornamentación y paisajismo y $A$. germinans, especie de importancia básica en la dinámica sucesional de suelos salinos y playas áridas, así como en los estudios fisiológicos debido a su tolerancia a la sal. El conocimiento complementario de las otras especies como $L$. racemosa, Mora oleifera y $P$. rhizophorae, así como las medidas gubernamentales de protección, contribuirán al manejo integral y sustentable de estos valiosos ecosistemas.
\end{abstract}

PALABRAS CLAVE:

Colombia, ecosistemas, manglares, recuperación, regeneración, silvicultura.

\begin{abstract}
A summary is given of the actual grade conditions and silvicultural experiences in the Colombian coast, with the species (Avicennia germinans, Conocarpus erectus, Laguncularia racemosa, Pelliciera rhizophorae y Rhizophora mangle) at the Caribbean coast; and the species (A. germinans, $P$. rhizophorae, $R$. spp.), at the Pacific Ocean coast. Due to disemination mechanism, main information belongs to red mangrove tree (R. mangle). It was also found that $C$. erectus as mangrove trees it is highly used in urban ornamentation scenery and landscape architecture, and $A$. germinans is essential in successional dynamics of salty soils and arid sea shores. Complementary knowledge of $L$. racemosa, $M$. oleifera and $P$. rhizophorae, as well as of the governmental protection measures, will contribute to the proper and sustainable management of these valuable mangrove ecosystems.
\end{abstract}

KEY WORDS:

Colombia, ecosystems, mangroves, restoration, regeneration, silviculture. 


\section{INTRODUCCIÓN}

En Colombia, de la variedad de tipos de bosques $\left(500000 \mathrm{~km}^{2}\right.$ aproximadamente), las áreas más importantes para el sector forestal son las regiones de Urabá, la cuenca del río San Juan y las del sur del Pacífico (entre Buenaventura y Tumaco) que representan más del $15 \%$ de la superficie boscosa (Neyra-Román, 1981; Gaviria-Flórez y González-Palacio, 1998). Sin embargo, las Reservas Forestales se han visto disminuidas en forma acelerada por el intenso aprobéchamiento forestal, la explotación minera y la colonización espontánea e intensa. Por esta razón y con el propósito de encarar los problemas de regeneración de los bosques naturales y establecer los servicios de apoyo a futuras reforestaciones, se planteó el Proyecto INDERENA/PNUD/ FAO-COL/74/005 en 1975.

La investigación silvicultural incluyó ensayos y experimentos de campo, desarrollo de métodos y sistemas silviculturales propios de los bosques húmedos tropicales tanto del Caribe como del Pacífico. No obstante, aunque se tuvieron en cuenta las asociaciones predominantes: (1) bosques de manglar, (2) bosque de guandal, (3) bosque de colinas bajas, (4) bosque de colinas altas, para el Pacífico, (5) bosque de catival y (6) bosques mixtos o de colinas en el Caribe, al final privó el hecho de contar con áreas propias para hacer seguimiento de regeneración natural, recurriendo a la colaboración de las empresas privadas relacionadas con actividades de aprovechamiento forestal, realizándose los trabajos de plantación de 18 especies, técnicas de vivero con 20 especies y regeneración natural en bosques de guandal (complejo de asociaciones vegetales de bosque pantanoso del Pacífico colombiano) donde se reconocen varios ecosistemas: (1) sajal (Campnosperma panamensis), (2) cuangariales (Otoba gracilipes), (3) naidizales (Euterpe oleracea), (4) guandales mixtos (Ceiba pentadra, Terminalia amazonia, Castilla elastica, Vochysia sp.), y cativales (Prioria copaifera), en asociaciones que directa o indirectamente tienen relación con el manglar (Neyra-Román, 1981; Del ValleArango, 1996).

A pesar de los valiosos aportes de la silvicultura colombiana en más de 300 especies tanto nativas como exóticas y la enorme producción documental de la última década (Silva, 1987), la existencia de trabajos sobre los esfuerzos en la silvicultura de los manglares en el país, es bastante escasa y en algunos aspectos inexistente.

La vulnerabilidad de los ecosistemas de manglar conformados por ocho especies (Avicennia germinans, Conocarpus erectus, Laguncularia racemosa, Pelliciera rhizophorae y Rhizophora mangle, en el Caribe y $A$. germinans, $C$. erectus, $L$. racemosa, Mora oleifera, $P$. rhizophorae, $R$. harrisoni, $R$. mangle y $R$. racemosa, en el Pacífico), y la constante presión a la que han sido sometidos por la acción antropogénica, han generado diversos ensayos para su recuperación en las costas colombianas.

Debido a las particulares condiciones climáticas y edáficas, los estudios han sido más frecuentes en el Caribe (AlvarezLeón, 1979, 1980, 1992, 1993, 1997), donde se han logrado avances en el conocimiento del área de Cartagena y de las Islas del Rosario, en cuanto a la propagación natural: mediante hipocótilos de Rhizophora mangle (Bohórquez-Rueda y Prada-Triana, 1986, 1987; JiménezCárdenas y Becerra-Rodríguez, 1987; INDERENA, 1991; Cañón-Escobar y Rodríguez-Cruz, 1994; Bohórquez-Rueda, 1994, 1996), así como de técnicas inducidas de transplante de plántulas de $R$. mangle (Bohórquez-Rueda y PradaTriana, 1986, 1988; Jiménez-Cárdenas y Becerra-Rodríguez, 1987; Cañón-Escobar y Rodríguez-Cruz, 1994), acodamiento y siembra de plántulas de $R$. mangle (González-Calderón y Rivas-Echeveverri, 1993a, 1993b), reacondicionamiento de 
suelos con Avicennia germinans, Laguncularia racemosa y $R$. mangle afectados por hidrocarburos (IbáñezGranados, 1992a, 1992b, 1995; Avendaño-Remolina y Sánchez-Arias, 1993, 1995; Sánchez-Arias et al., 1996; Grosso-Vargas et al., 1995a, 1995b, 1996a, 1996b), manejo y almacenamiento de embriones de semillas recalcitrantes de $A$. germinans, $L$. racemosa y $R$. mangle (Serna-Terán, 1998) y aspectos bioquímicos como la acción de las poliaminas sobre el crecimiento de plántulas de $R$. mangle (Mendoza-Forero, 2000 y Mendoza Forero et al., 2002).

Observaciones realizadas por Giraldo (1995) en la Ciénaga Grande de Santa Marta y sus áreas de influencia, permitieron reconocer las épocas de mayor abundancia de propágulos $/ \mathrm{m}^{2}$, los rangos de variabilidad de la implantación de propágulos $/ \mathrm{m}^{2}$, crecimiento y mortalidad en $A$. germinans y $R$. mangle, así como la supervivencia de plántulas por regeneración natural e inducida con propágulos de $A$. germinans, $L$. racemosa y $R$. Mangle; otro tanto realizaron también Elster et al. (1996). En la misma zona, Ensminger (1996), Elster (1997, 1998a, 1998b, 2000, 2001), Elster y Schnetter (1998) y Elster et al. (1999a, 1999b), analizaron la hidrología y su dinámica antes y después de las obras de limpieza y adecuación de caños en la zona norte; Perdomo-Trujillo (1996) registró las experiencias de siembra y transplante de los manglares del área; Schubert (1998) analizó la dispersión de propágulos y la presencia de plántulas de $R$. mangle, $A$. germinans y $L$. racemosa, después de la apertura de caños; Castañeda-Moya (1998) investigó sobre fenología reproductiva de $A$. germinans y $R$. mangle; Elster y Perdomo-Trujillo (1998) sobre fenología reproductiva de $L$. racemosa; Casas-Monroy (1999), Perdomo-Trujillo et al. (1999) y Perdomo-Trujillo (2001) sobre regeneración natural de $A$. germinans, $L$. racemosa y $R$. Mangle; Arango-Estévez (2001) sobre repoblamiento experimental de R. mangle; Elster et al. (1999a, 199b) y
Campos (2001) sobre herbivoría en $A$. germinans; y Elster y Polanía-Vorenbeg (2000) sobre las posibilidades de recuperación de los manglares de la Ecoregion de la CGSM.

En el Pacífico colombiano, en cambio la tendencia ha sido el esperar la regeneración natural de las áreas intervenidas (INDERENA, 1991) o usar hipocótilos y plántulas de Rhizophora spp. y viveros comunitarios en la zona de Tumaco (Nariño) (Rodríguez-Cruz, 2002). En el Valle del Cauca, estudios sobre la implantación de plántulas de cuatro especies de manglar (A. germinans, Conocarpus erectus, Pelliciera rhizophorae, Rhizophora spp.) permitieron conocer en cuatro estaciones, 20 parcelas $(4 \times 4)$ y 244 individuos, sus particularidades en cuanto a la abundancia, relación sustrato/ especie, factor hidrodinámico, selección de partículas y salinidad intersticial (Correa et al., 2002.). Marín-Restrepo (1998) realizó un análisis preliminar de la regeneración natural y de los suelos del manglar en la Isla Grajales, Delta del Río San Juan.

Recientemente, el Proyecto Manglares de Colombia en su Fase II (Etapas I y II) entre 1998 y 1999, ha impulsado activamente la restauración de áreas degradadas de manglares, realizando su trabajo con la activa participación comunitaria y de las 12 corporaciones regionales. (Guevara-Mancera, 1998; Ulloa-Delgado et al., 1998b; SánchezPáez et al., 2000; Sánchez-Páez y UlloaDelgado, 2000).

Después de realizar el correspondiente transplante de la zona del Canal del Dique (Bol.) a la zonas de Barrancabermeja (Sant.) y Toldao (Tol.), con una mortalidad inferior al $2 \%$ del mangle rojo (R. mangle) proveniente del Canal del Dique (Bol.), se han utilizado con éxito en la recuperación y restauración de áreas afectadas por alta salinidad (GrossoVargas et al., 1995a; 1996b), contaminantes y metales pesados de las aguas 
de perforación (Grosso-Vargas et al., 1995b, 1996a).

Los tratamientos silviculturales más adecuados para el manejo del manglar deben ser bastantes flexibles, con el fin de proceder en cada caso, conforme a las necesidades locales, tan variadas en Colombia, de región a región y aún dentro de un mismo rodal de manglar. Tradicionalmente se ha considerado que los manglares cumplen importantes funciones de protección contra la erosión hídrica y eólica de los suelos costeros o ribereños y que ayudan a crear nuevas tierras (Bascope et al., 1959; Savage, 1972; Autry et al., 1973; Carlton, 1974; Rabinowitz, 1974). Por tanto las experiencias realizadas con los géneros americanos Rhizophora, Laguncularia y Avicennia se han desarrollado con ese fin primario (Egler, 1948; Pulver, 1976; Thorhaug, sf) e, indirectamente, para devolver a dichas áreas su importancia como productores primarios y base de una compleja red alimenticia, que aún no es suficientemente conocida.

\section{Estado de los rodales}

Con el objeto de conocer el estado de los manglares colombianos, el Instituto Nacional de Recursos Naturales Renovables y del Ambiente (INDERENA) a través de su Subgerencia de Bosques y Aguas utilizó el método malayo (FAO, 1970). Este método sirve para determinar y seleccionar aquellas especies destinadas al manejo silvicultural y requiere el cálculo de la Estimación Mínima Confiable (EMC). Según Falla-Ramírez (1970), el método puede aplicarse al estudio de la dinámica de los bosques de manglar en las etapas de brinzal (altura < $1.5 \mathrm{~m}$; diámetro < $5 \mathrm{~cm}$ ), latizal (altura 1.5-3.0 m; diámetro $5-15 \mathrm{~cm}$ ) y fustal (altura $>3 \mathrm{~m}$; diámetro $>15 \mathrm{~cm}$ ), expresando en porcentaje el número de sitios ocupados con especies deseables, para determinar el tipo de práctica y tratamiento silvicultural que se requiere.
El estudio realizado por INDERENA (1991), incluyó el diagnóstico, dinamismo y tendencia y se basó en observaciones cualitativas (composición florística, cobertura y estado) y en parámetros cuantitativos (altura, diámetro, densidad y área).

Etapa de Brinzal. En general existe una buena abundancia de brinzales en las dos costas, siendo más abundantes en los Departamentos de Cauca y de Valle del Cauca en el Pacífico y Departamentos de Córdoba y de Sucre en el Caribe. Los promedios obtenidos para el Caribe y el Pacífico alcanzaron las cifras de 12625 y 20300 plántulas/ha. De acuerdo con el método malayo, cuando se observa una ocupación del 40 \% EMC (1 000 brinzales/ ha) se considera suficiente la regeneración natural para que en las siguientes etapas haya latizos y fustales que garanticen buenas posibilidades al final de cada ciclo de rotación o turno de corta. La altura promedio también fue superior en el Pacífico $(0,77 \mathrm{~m})$ que en el Caribe $(0,59$ $\mathrm{m})$, notándose que por su abundancia, la etapa requiere prácticas y tratamientos silviculturales de manejo, para asegurar el éxito en las fases siguientes (INDERENA, 1991).

Etapa de Latizal. Los promedios obtenidos para el Caribe y el Pacífico fueron 1149 y 1655 latizos/ha respectivamente, siendo mayor la abundancia y ocupación en los Departamentos del Valle del Cauca y Córdoba. Lo anterior indica que la ocupación por unidad de superficie (>280 latizos/ha) es aceptable según el método malayo aplicado; sin embargo, se debe destacar que debido a la extracción de varas y varetas predomina un latizal raquítico y mal conformado, observándose en general desfases en altura, diámetro e individuos deformes. También la altura de los latizos del Pacífico $(2,80$ $\mathrm{m})$ es superior a la de los del Caribe $(2,30$ $m$ ), observándose que esta etapa necesita tratamientos y prácticas silvi-culturales en cuanto al manejo del diámetro, altura y buena conformación de los latizos, que 
aseguren su paso a la fase de fustal (INDERENA, 1991).

Etapa de Fustal. Para esta etapa, los promedios para el Caribe y el Pacífico alcanzaron los 197 y 244 fustales/ha respectivamente, que corresponden a árboles remanentes no extraídos por presentar individuos con deformaciones o diámetros y alturas no requeridos comercialmente (pilotes y postes). De acuerdo con el método malayo, los fustales estarían por debajo del límite crítico (280 fustales/ha), por lo que requiere prácticas y tratamientos silviculturales para normalizar la tendencia de la sucesión vegetal y su etapa final. Serán básicas las medidas de protección que se impongan en forma inmediata, así como las severas restricciones para la obtención de productos en esta etapa sucesional (INDERENA, 1991).

Inventario Forestal. Existen diversas cifras sobre las áreas ocupadas por los ecosistemas de manglar y para su obtención se han aplicado diversos métodos complementarios (Alvarez-León, 1993). Sin embargo, al comparar las dos cifras nacionales incluidas en los Mapas de Bosques (IGAC, 1966, INDERENA et al., 1984) con 501300 ha y las de la evaluación del INDERENA (1991) con 365902 ha, en el curso de 17 años se habrían talado 135398 ha, a un ritmo de deforestación de 7965 ha/año. La cifra anterior incluye las áreas degradadas o en proceso de destrucción pero son un índice del problema que se enfrenta, con talas de 218 ha/día y que equivaldrían a que entre 1984 y 1991 se habrían destruido alrededor de 55765 ha más (INDERENA, 1991).

La evaluación nacional más reciente se debe al Proyecto Manglares de Colombia MMA/OIMT, que entre 1995 y 1996 logró precisar con base en trabajo de campo, cartografía, fotografía aérea, imágenes del radar INTERA para el Pacífico e imágenes del satélite LANDSAT para el Caribe, que la cobertura nacional de manglares asciende a 379028 ha (86 310,50 ha en el Caribe y 292 724,39 ha en el Pacífico). Para el Pacífico se realizó una evaluación multitemporal entre 1969 (306 436,6 ha) y 1996 (292 724,4 ha), que permitió determinar una pérdida de 13 712,2 ha en 27 años y que del total en 1996 existen 27 337,11 ha con reducciones y alteraciones antrópicas; en el Caribe se detectó que del total, existen 21921,50 ha con problemas de morta-lidad (ZambranoEscamilla y Rubiano-Rubiano, 1996 y 1997; Sánchez-Páez et al., 1997a y 1997b).

Aprovechamiento Forestal. Las actividades forestales en los manglares colombianos se remontan a mediados del siglo pasado. No obstante que existen semejanzas en el aprovecha-miento artesanal en cuanto a las partes aprobéchadas del arbolado y su posterior utilización, difieren fundamentalmente en el aprovechamiento industrial y semiindustrial. Mientras en el Caribe se aprovechaba para la fabricación de carbón activado y las astillas de la madera, para fabricación de tableros aglomerados con un total desperdicio de la corteza, en el Pacífico se utilizaba la corteza para extraer los taninos, desperdiciando totalmente la madera. Las actividades forestales sin planificación y con baja o nula ordenación y manejo, ocasionaron sobre-explotación y gran deterioro al ecosistema, tanto desde el punto de vista de su productividad como de su impacto socioeconómico, dado que las comunidades locales dependen de la extracción de productos pesqueros y forestales. En el litoral del Caribe, el aprovechamiento industrial se suspendió a partir del 1979 (Hernández-Camacho et al., 1978a, 1978b), en el Pacífico en cambio, subsistían permisos vigentes para aprovechar mangle rojo (Rhizophora spp.) con destino a la fabricación de postes, pilotes y vigones (Dptos. del Chocó: 3742 $\mathrm{m}^{3}$, Valle del Cauca: $4714 \mathrm{~m}^{3}$; Cauca: $2637 \mathrm{~m}^{3}$ ) de madera rolliza (redonda) (Chocó: $1371 \mathrm{~m}^{3}$ ) y extracción de corteza (Cauca: $380 \mathrm{~m}^{3}$ ) (INDERENA, 1991). 
Actualmente, el aprovechamiento artesanal de mangle en las costas colombianas, se realiza para la obtención de madera, que es utilizada en fabricación de carbón, leña y para la industria de la construcción (varas, vigones, horcones, pilotes) y postes para redes eléctricas. Los manglares constituyen una fuente estable de ingresos indirectos de subsistencia para comunidades de pescadores y corteros que en los dos litorales, tradicionalmente, han convivido con estos sistemas vegetales. En el Departamento del Chocó sólo se expiden permisos para el aprovechamiento del manglar a las Comunidades Negras.

En el Caribe colombiano, sólo en el Departamento de Córdoba, la Corporación Autónoma Regional del Sinú (CVS) permite el aprovechamiento forestal de los manglares de la Bahía de Cispatá, por parte de dos cooperativas de mangleros y de acuerdo con un estudio previo del estado de los rodales y sus correspondientes monitoreos (Vélez-Escobar, 1990, 1991, 1993, 1994).

Existen dos vedas para el aprovechamiento de los manglares en el Pacífico colombiano, una de la CVC en el Departamento del Valle del Cauca mediante el Acuerdo CD-024 (Julio 18 de 1997) que prorrogó por tres años la veda temporal (Acuerdo 018 de agosto 14 de 1995), que incluye el aprovechamiento, movilización y comercialización de los productos provenientes del ecosistema manglar, y la otra de CORPONARIÑO para el Departamento de Nariño mediante la Resolución 037 (Febrero 9 de 1998) que establece una veda temporal de tres años.

Problemática Ambiental. La construcción de obras civiles especialmente en cuanto a vías de comunicación como carreteras, canales y vías férreas en la costa Atlántica principalmente, así como la edificación y adecuación de muelles, la ampliación de centros urbanos, han contribuido a la desaparición y degradación de los bosques de manglar (INDERENA, 1991; Yanine-Díaz, 1991).

En el Caribe, debido a su desarrollo económico y social, los impactos sobre los ecosistemas han ido adquiriendo proporciones devastadoras. Basta considerar las principales áreas afectadas y sus causas: (1) Troncal del Caribe entre Barranquilla y Ciénaga, trazada a través de importantes áreas de manglar de la Isla de Salamanca y la Ciénaga Grande de Santa Marta, (2) Vía Coveñas y Tolú, a través de áreas de manglar de las ciénagas La Caimanera y El Francés, (3) La comunicación de Cartagena y Barranquilla a través del denominado Anillo Vial a través de los manglares de la Ciénaga de La Virgen o de Tesca, (4) La construcción y adecuación de los muelles en la Bahía de Cartagena (53 en total, hasta 1995) y Turbo, (5) los dragados y rectificaciones del Canal del Dique, (6) la construcción de camaroneras en el Canal del Dique, Isla Barú, Bahía de Barbacoas y Bahía de Cispatá, (7) la ampliación de centros urbanos sobre las zonas de manglar, tales como Cartagena, Coveñas, Tolú y Turbo y, (8) la adecuación de áreas para el turismo, como construcción de hoteles, casas de campo, marinas, especialmente en las Islas de San Andrés, del Rosario y de San Bernardo, lo que ha causado fuertes impactos detectados en los litorales continentales de los Departamentos de Bolívar, Sucre y Córdoba.

En el Pacífico con un desarrollo menor sobre la zona costera, los impactos sobre los ecosistemas de manglar han sido relativamente menores. Sin embargo, a continuación se mencionan las principales áreas afectadas y sus causas: (1) Construcción y ampliación de centros urbanos sobre las zonas de manglar (Buenaventura, Tumaco, Bahía Solano); (2) Construcción de camaroneras en las áreas de Guapi y Tumaco; (3) Construcción y adecuación de muelles en las Bahías de Buenaventura, Tumaco y Málaga; (4) Ejecución de los permisos de 
aprovechamiento forestal vigentes, en los Departamentos de Chocó, Valle del Cauca y Cauca y, (5) Ampliación de las fronteras agrícola (Dptos. Valle del Cauca, Cauca y Nariño) y minera (Dpto. del Chocó).

\section{Proyecto Manglares MMA/CONIF/OIMT}

Entre septiembre de 1995 y junio del 2000 se llevó a cabo en las costas colombianas el Proyecto PD 171/91 Rev. 2 (F) Conservación y Manejo para el Uso Múltiple y el Desarrollo de los Manglares en Colombia en sus Fases I y II (Etapas I y II), auspiciado y financiado por el Ministerio del Medio Ambiente(MMA) y la Organización Internacional de Maderas Tropicales (OIMT), y en estrecha colaboración con la Corporación Nacional de Investigación y Fomento Forestal (CONIF), la Asociación Colombiana de Reforestadores (ACOFORE) y las Corporaciones Regionales (CAR's y CDS's) .

Durante la Fase I se realizó el diagnóstico, zonificación preliminar, cartografía y análisis socio-económico, de los manglares y la gente de los manglares colombianos. Así mismo, pudo precisarse que el área cubierta por manglar en los 14 Departamentos costeros de los dos litorales, asciende a 379 349,9 ha. Repartidos en litoral Caribe que posee 86 310,5 ha (Guajira con 3 131,2 ha; Magdalena con 52 477,7 ha; Atlántico con 336,9 ha; Bolívar con 5 704,9 ha; Sucre con 9 574,3 ha; Córdoba con 8 862,2 ha; Antioquia con 6 084,7 ha; Chocó con 41,6 ha; San Andrés y Providencia con 97,0 ha) y en el litoral Pacífico el cual posee 292 724,4 ha (Chocó con 64 750,5 ha; Valle del Cauca con 41 961,4 ha; Cauca con 36 276,8 ha; Nariño con 149 735,8 ha) (Sánchez-Páez et al., 1997a, 1997b).

Dinámica del crecimiento y regeneración natural. En la costa Caribe se establecieron 25 parcelas permanentes de crecimiento, en las cuales los incrementos anuales en diámetro fueron de $0,5 \mathrm{~cm}$ para $A$. germinans; $0,49 \mathrm{~cm}$ para $L$. racemosa y $0,46 \mathrm{~cm}$ en $R$. mangle, correspondientes a árboles de $14 \mathrm{~cm}$ de diámetro promedio, ubicados en la Ciénaga Honda en el Municipio de Arjona (Bol.). En general, los árboles con menores diámetros promedio manifestaron los más altos incrementos anuales para este parámetro. Todas las parcelas permanentes de crecimiento presentaron un diámetro a la altura del pecho (DAP) promedio inferior a $8 \mathrm{~cm}$. En dichas parcelas y para las tres especies, el incremento neto anual registrado en diámetro fue de $0,36 \mathrm{~cm}$.

En la Guajira, se registraron valores muy bajos de regeneración natural entre 0,28 y 0,35 propágulos $/ \mathrm{m}^{2}$, siendo $L$. racemosa la más frecuente. En el Magdalena se registraron valores, entre 0,39 y 2,66 propágulos $/ \mathrm{m}^{2}$. En Bolívar se hallaron valores altos, entre 0,87 y 39,41 propágulos $/ \mathrm{m}^{2}$, siendo $R$. mangle la más abundante, seguida por $L$. racemosa y $A$. germinans. En Córdoba se obtuvieron los mayores registros con 88,16 propágulos $/ \mathrm{m}^{2}$ con fructificación muy abundante de $L$. racemosa (Ulloa-Delgado et al., 1998a, 1998b).

Para la costa Pacífica se establecieron 27 parcelas permanentes de crecimiento, siendo la especie más representativa el mangle rojo ( $R$. mangle), con árboles de $23,5 \mathrm{~cm}$ promedio de diámetro, que arrojaron un incremento anual promedio en diámetro de 0,31 cm/año. (Guevara-Mancera, 1998; GuevaraMancera et al., 1998).

También se establecieron 27 subparcelas de $4 \mathrm{~m}^{2}$ para el estudio de la regeneración natural realizando registros durante siete meses en diferentes áreas de Nariño, se encontraron diferencias significativas en la disponibilidad de propágulos de Rhizophora spp., las cuales estuvieron directamente relacionadas con la fructificación estacional de la especie; la implantación y el reclutamiento de plántulas parece, en cambio, estar más 
relacionadas con la presencia de árboles maduros. En general, Rhizophora spp. presentó un descenso notorio en la implantación de propágulos, la cual coincidió con el período de lluvias más intenso en la región (Guevara-Mancera et al., 1998).

Durante la Fase II (Etapas I y II), con base en el conocimiento adquirido sobre las zonas degradadas y el interés de las comunidades por colaborar en las acciones conducentes a su restauración, se identificó como prioritaria la realización de ensayos de recuperación de las áreas de manglar en las dos costas, con la activa participación de las comunidades locales.

\section{Esfuerzos nacionales en la recuperación}

Varias acciones se han venido desarrollando por parte de diversas instituciones del Gobierno Nacional y de entidades privadas, con el objeto de proteger los ecosistemas de manglar. Dentro de estos esfuerzos se hallan: (1) la declaratoria de Parques Nacionales, Santuarios de Fauna y Flora, Reservas Forestales, Areas de Manejo Especial y Áreas Exclusivas de Pesca Artesanal, con el fin de preservar áreas de especial interés como reservas genéticas representativas de la biota regional, productivas, escénicas y paisajísticas; (2) la celebración de reuniones científicas nacionales e internacionales dentro de las cuales, además de crear conciencia, se divulguen los resultados de las investigaciones realizadas; (3) el reconocimiento creciente por parte de las autoridades, de la importancia ecológica de estos ecosistemas, al aplicarse la Legislación Forestal vigente; (4) la formulación de un Plan Nacional de Manglares por parte del INDERENA en 1992, el cual asume acciones a corto plazo (veda total del aprovechamiento y conformación del Comité Nacional de Manglares), a mediano plazo (ejecución de tres proyectos: Ordenación y Manejo para el Uso Múltiple y Conservación de los Manglares en Colombia, a la organización Internacional de Maderas Tropicales; Grupos Técnicos de Supervisión y Asistencia Técnica Forestal, al Banco Mundial; y Diversidad Natural de la Región del Chocó Biogeográfico) y a largo plazo (Ordenación Territorial y Zonificación Detallada de los Manglares de Colombia); (5) auspiciar la realización de estudios tendientes a recuperar las zonas de manglar, intervenidas por cualquier causa (INDERENA, 1991; Alvarez-León, 1993), (6) inclusión de la zona costera y sus ecosistemas en la Estrategia Nacional sobre la Biodiversidad; así como la adhesión al Convenio Mundial sobre Biodiversidad y aprobación de la Ley 165 de 1994 y a la Convención Relativa a los Humedales de Importancia Internacional Especialmente como Hábitat de Aves Acuáticas, suscrita en RAMSAR y la aprobación de la Ley 347 de 1997; (7) promulgación a través del Ministerio del Medio Ambiente de las Resoluciones 1602 de 1995, 020 de 1996, 257 y 924 de 1997 y 233 de 1999, por medio de las cuales se dictan las medidas para garantizar la sostenibilidad de los manglares nacionales, (8) Formulación de los términos de referencia para que las Corporaciones Autónomas Regionales completen el diagnóstico actualizado del estado y zonificación de los manglares en Colombia, para su adecuado manejo y (9) Promulgación de las Políticas Nacionales para el Manejo y Administración de las Zonas Costeras en 1998 por parte del Ministerio del Medio Ambiente y de las Ciencias y las Tecnologías del Mar 19992004 por parte de COLCIENCIAS y la Comisión Colombiana de Oceanografía, además de las vedas al aprovechamiento del manglar en los Departamentos del Valle y de Nariño.

\section{Prácticas de recuperación}

Actualmente la presión sobre las áreas de manglar se mantiene vigente, a pesar de las medidas técnicas y legales de control establecidas por el INDERENA 
hasta 1993 y el Ministerio del Medio Ambiente y las Corporaciones a partir de 1994. En el Pacífico la utilización de las tierras costeras, la ejecución de los permisos de aprovechamiento forestal artesanal actualmente vigentes $y$ el inevitable aprovechamiento ilegal, han colaborado para que dicha presión no disminuya.

En el Caribe en cambio las acciones han respondido a la necesidad de conocer en detalle las respuestas de las especies ante condiciones extremas y su viabilidad. En la Isla de Salamanca a partir de la iniciación de los trabajos de recuperación del complejo deltaico del río Magdalena y el restablecimiento del balance halohídrico del ecosistema (Moreno-Bejarano, 1984; Sánchez-Paéz, 1988) funcionarios del INDERENA efectuaron pequeños ensayos de propagación de hipocótilos de $R$. mangle con relativo éxito (MorenoBejarano, 2002) entre 1984 y 1985.

En el Archipiélago de las Islas del Rosario, con ocasión de la adecuación de áreas para el turismo y la construcción de casas de campo, se han destruido o erradicado varias áreas de manglar; en ese lugar se han realizado tres experiencias tendientes a contribuir a su recuperación: entre 1984 y 1985 con la utilización de hipocótilos y plántulas de $R$. mangle (Bohórquez-Rueda y PradaTriana, 1986, 1987, 1988), en 1987 también con hipocótilos y plántulas de $R$. mangle, así como la práctica de poda experimental (Jiménez-Cárdenas y Becerra-Rodríguez, 1987), en 1992 y 1993 con plántulas de $R$. mangle obtenidas por acodamiento (GonzálezCalderón y Rivas-Echeverri, 1993a, 1993b) e hipocótilos de $R$. mangle, propágulos de $L$. racemosa y $A$. germinans, semillas de $C$. erectus y plántulas de las cuatro especies (CañónEscobar y Rodríguez-Cruz, 1994).

En la Bahía de Cartagena (Bol.) se valoró una técnica para la recuperación de suelos de manglar afectados drásticamente por hidrocarburos que, a su vez, han sufrido procesos de erosión, compactación e hipersalinización; la bioestimulación (biodegradación estimulada con bacterias) combinada con una posterior saturación de los suelos dio los mejores resultados sobre las plántulas de $L$. racemosa y $A$. germinans (AvendañoRemolina y Sánchez-Arias, 1993). También se han desarrollado experiencias de adaptación y recuperación forestal y pedológica de áreas afectadas por aguas residuales de campos de producción de petróleo, lodos de excavación y derrames de hidrocarburos en la Bahía de Cartagena (Bol.), Barrancabermeja (Sant.) y Toldado (Tol.) (Avendaño-Remolina y Sánchez-Arias, 1993, 1995; SánchezArias et al., 1996; Grosso-Vargas et al., 1995a, 1995b, 1996a, 1996b ).

Como puede observarse, los resultados comienzan a proporcionar la información inherente a cada especie, su desarrollo y hábitos de crecimiento. Vale la pena aclarar que para varias de las experiencias, se han utilizado hipocótilos, propágulos y plántulas del Canal del Dique, tradicionalmente considerado como el vivero ideal por sus características fluvio-deltáicas en sus desembocaduras a las Bahías de Barbacoas (Caños Correa, Matunilla y Lequerica) y de Cartagena (canal a la altura de Pasacaballos).

Según las experiencias realizadas por el Proyecto Forestal del INDERENA Regional Bolívar en Cartagena (Bol.), $R$. mangle es la mejor especie para recuperación forestal costera, por su capacidad de resistir condiciones extremas, supervivencia en vivero y disponibilidad; le siguen en importancia y condiciones $A$. germinans, $L$. racemosa y $C$. erectus, aunque las dos últimas responden mejor al transplante de plantas (1-5 m) defoliadas y bola de tierra, así como por el método de estacas y acodos (Pallares, 2002). 
Las observaciones y experiencias en el Pacífico colombiano (1990-1991 y 1994-1995) en el sur del Departamento de Nariño, auspiciado por la Corporación Autónoma Regional de Nariño, CORPONARIÑO y las comunidades de corteros y leñateros del manglar permitieron conformar tres viveros comunitarios en los barrios Unión Victoria y San Vicente de las Varas de Tumaco (Nariño) y Salahonda en Francisco Pizarro (Nariño). Se utilizaron cuatro especies (Rhizophora spp., L. racemosa, $A$. germinans y $M$. oleifera), se hizo el seguimiento del crecimiento y se están trasplantando plántulas a las áreas impactadas por el aprovechamiento comunitario y en los diques de las camaroneras artesanales (Rodríguez-Gómez, 2002). El manejo adecuado de estas particularidades así como otras del entorno, permitirán mantener la producción sostenida del bosque natural y darle aprovechamiento sostenido y prácticas silviculturales apropiadas (De Las Salas, 1987; Lamprecht, 1990).

Atendiendo a una necesidad nacional se creó a partir de la Ley 139 de 1994, el Certificado de Incentivo Forestal (CIF), con el propósito de estimular la reforestación, como actividad para promover la protección del medio ambiente y crear nuevas fuentes de trabajo e ingresos. A través de las Resoluciones 711 de 1994 y 186 de 1995 se listaron las especies forestales nativas y exóticas, que pueden ser objeto de otorgamiento del CIF a través de programas de reforestación, entre las cuales se incluyeron los mangles negros (Avicennia), blancos (Laguncularia) y rojos (Rhizophora). Así mismo, la Ley 139 de 1994 ha sido reglamentada a través del Decreto 1824 de 1994, resoluciones 448 y 822 de 1995, la Ley 223 de 1995 y el Decreto 1044 de 1996 que buscaron incentivar tanto las labores de reforestación como de protección de los bosques naturales. Es bien conocido que otorgando incentivos y estímulos a la inversión privada y a la competitividad de las actividades agrícolas, pecuarias, pesqueras y forestales, en diciembre de 1995, países reunidos por convocatoria de la FAO, llegaron a la conclusión de que generalmente en aquellos países donde se han aplicado incentivos forestales con relativo éxito, los impactos socioeconómicos y ambientales han sido positivos, especialmente políticas macroeconómicas y sectoriales, infraestructura, educación y capacitación, desarrollo tecnológico, entre otros (FAO, 1996).

Merecen especial mención los estudios realizados sobre la ecofisiología del manglar, específicamente del mangle salado ( $A$. germinans). La observación, medición y análisis de los parámetros climáticos y edáficos que afectan la especie en la Isla de Salamanca (Mag.) fueron realizados por Schnetter (1969, 1978). Posteriormente y con base en hipocótilos de esta misma zona, el Parque Tayrona (Mag.) y Turbo (Ant.) ha profundizado y perfeccionado sus observaciones en Alemania (Laboratorio de Botánica, Universidad de Giessen) detallando las fases vivípara y autónoma, así como el efecto de la salinidad y el $\mathrm{pH}$ en el crecimiento, especialmente utilizando cultivos hidropónicos (Schnetter, 1985; 1986; 2002). Para concluir con este tema, se incluye una tabla con las experiencias inéditas de recuperación que son del conocimiento del autor, comunicadas por las fuentes citadas (Tabla 1).

\section{Proyecto manglares MMA/ACOFORE/OIMT}

Con base en el diagnóstico, la zonificación, el mapeo y el análisis socioeconómico, realizado durante la Fase I del proyecto (Sánchez-Páez et al., 1997a, 1997b), se identificó como prioritaria, la realización de ensayos de recuperación de las áreas de manglar en las dos costas, con la activa participación de las comunidades locales. Durante la Fase II (Etapas I y II), se perfeccionaron las técnicas, revisando continuamente las parcelas y ampliando la cobertura de las áreas de recuperación (inicialmente en los 
Departamentos de Bolívar, Sucre y Córdoba) a los Departamentos de Magdalena, Atlántico, Antioquia y San Andrés y Providencia.

Restauración de áreas de manglar. En la costa del Caribe, en parcelas de restauración con $R$. Mangle, se registró una supervivencia de $100 \%$ para plántulas en vivero y de $87,34 \%$ para la plantación en una parcela, del $81 \%$ en vivero y $95 \%$ en plantación en otra parcela y de $67,36 \%$ para siembra directa en otra parcela. El desarrollo de las plántulas de $R$. mangle alcanzó tasas acumuladas de $1,60 \mathrm{~mm}$ por día. Para $A$. germinans se obtuvo un crecimiento de $42,67 \mathrm{~cm}$ y para Rhizophora de $45,78 \mathrm{~cm}$ a los 270 días, obteniéndose mejores resultados en el trasplante con plántulas provenientes de vivero, en comparación con aquellas que se obtuvieron por siembra directa de propágulos (UlloaDelgado et al., 1998a, 1998b; SánchezPáez y Ulloa-Delgado, 2000).

En la costa Pacífica los ensayos también fueron más exitosos con material vegetal producido en vivero, los cuales presentaron una respuesta más positiva con respecto a plántulas producidas por siembra directa, con una supervivencia para $R$. mangle de $94 \%$ y de $84 \%$, respectivamente, superando además a las otras tres especies, pues $L$. racemosa apenas alcanzó un 3,4 \%, con el método de siembra directa. En el caso de material de vivero la supervivencia en el área del transplante para A. germinans fue de $42 \%$ y para $P$. rhizophorae de $96,3 \%$. En las parcelas analizadas, $A$. germinans presentó respuesta de supervivencia en siembra directa de $52,3 \%$ después del primer mes y de $44,3 \%$ tras un período de 3 meses. En siembra directa, a los cinco meses, se obtuvieron plántulas de $34 \mathrm{~cm}$ promedio en altura y máximo de 80 $\mathrm{cm}$, para $R$. mangle, mientras que en material de vivero el promedio fue de 38,9 $\mathrm{cm}$ y el máximo de $83 \mathrm{~cm}$ (Sánchez-Páez et al., 1997b; Guevara-Mancera et al., 1998).
Viveros temporales. Para el litoral Caribe se instalaron inicialmente, cinco viveros temporales comunitarios en los Departamentos de Bolívar, Sucre y Córdoba. Pasacaballos (Bol.) de $14 \mathrm{~m} \times 14 \mathrm{~m}$ para 24000 plántulas; Leticia (Bol.), Canal del Dique (Bol.) de $10 \mathrm{~m} \times 5 \mathrm{~m}$ para 7000 plántulas; Isla del Rosario (Bol.) $4 \mathrm{~m} \mathrm{x} 4 \mathrm{~m}$ para 4000 plántulas; Boca Cerrada (Sucre) 10 m x 7 m para 12000 plántulas; Los Cocos (Parque Nacional Natural Isla de Salamanca) (Mag.) $4 \mathrm{~m} \times 4 \mathrm{~m}$, para 7000 plántulas y Caño de Lobo (Córdoba), de $14 \mathrm{~m} \times 12$ para 24000 plántulas. La producción de plántulas corresponde a un período de 75 días, tiempo en el cual son aptas para ser trasplantadas. Todos estos viveros ya han tenido dos ciclos de producción con muy buenos resultados. (Rodríguez-Cruz, 1998; Ulloa-Delgado et al., 1998a, 1998b).

En 1998 durante la Fase II (Etapa I) del proyecto se restauraron 35 ha de playones aluviales en cercanías de los Caños Matunilla y Lequerica, y en la Bahía de Cispatá. En los seis primeros meses de 1999 (Fase II, Etapa II) se han instalado seis viveros, cuatro de ellos en el Antiguo Delta Estuario del Río Magdalena, uno en Necoclí (Ant.) y otro en San Andrés, y se ha logrado la restauración 35 ha. nuevas en los mismos lugares antes mencionados: Este trabajo se ha efectuado con el concurso y participación activa de las comunidades locales y las Corporaciones. Datos más amplios y detallados sobre estos trabajos de restauración serán objeto de una publicación por parte de los consultores del proyecto de la regional Caribe.

En la costa Pacífica, en los alrededores de Tumaco (Nariño) se adecuaron los tres viveros previamente construidos por CORPONARIÑO y se construyeron dos en el Cauca. Estos últimos de $5 \mathrm{~m} \times 5 \mathrm{~m}$ y de $7 \mathrm{~m} \times 7 \mathrm{~m}$ para una capacidad de 150 y 2500 plántulas en bolsas de polietileno, respectivamente. 
Tabla 1. Experiencias inéditas de recuperación con manglares en las costas continentales e insulares de Colombia

\begin{tabular}{|c|c|c|c|c|c|}
\hline $\begin{array}{c}\text { LUGAR } \\
\text { Localidad (Depto.) }\end{array}$ & $\begin{array}{l}\text { ÁREA } \\
\text { (ha) }\end{array}$ & TENSOR & ESPECIE (S) & METODO (S) & $\begin{array}{l}\text { FUENTE (com. } \\
\text { pers.) }\end{array}$ \\
\hline Lomarena (Bol.) & 10 & $e, c$ & $\mathrm{Ce}$ & $\begin{array}{l}\text { es, tr } \\
(1-2 \mathrm{~m})\end{array}$ & PRODECOSTA \\
\hline $\begin{array}{l}\text { Bahía de Cartagena y } \\
\text { Ciénaga de la Virgen (Bol.) }\end{array}$ & $5-6$ & $t, r$ & $\mathrm{Lr}, \mathrm{Rm}$ & $\operatorname{tr}(1-3 m)$ & A. Cabarcas \\
\hline Ciénaga de la Virgen (Bol.) & $1-2$ & $t, r, q$ & $\mathrm{Rm}$ & hi & J. H. Sánchez \\
\hline $\begin{array}{l}\text { Ciénaga Grande de Santa } \\
\text { Marta (Mag.) }\end{array}$ & 1 & $t, r$ & $\mathrm{Rm}$ & hi & A. Pallares \\
\hline Caño Juan Angola (Bol.) & 0.5 & $t, r$ & $\mathrm{Ce}$ & $\operatorname{tr}$ & A. Pallares \\
\hline Boquilla (Bol.) & 1 & $t, r$ & $\mathrm{Rm}$ & hi & A. Pallares \\
\hline Ciénaga de Cholón (Bol.) & 1 & $t, r, c$ & $\mathrm{Rm}$ & hi, tra & A. Pallares \\
\hline Isla Arena (Bol.) & $2-3$ & e & $\mathrm{Ag}, \mathrm{Lr}, \mathrm{Rm}$ & $\mathrm{pl}$ & $\begin{array}{l}\text { L.G. Cano, } \\
\text { G.M. Cañón y } \\
\text { H. Rodríguez }\end{array}$ \\
\hline Bahía de Cispatá (Cor.) & 1 & $\mathrm{t}, \mathrm{r}, \mathrm{h}$ & $\mathrm{Rm}$ & hi, tr & C.V.S \\
\hline Punta Iguana (Bol.) & 0,2 & $r$ & $\mathrm{Rm}$ & $\operatorname{tr}(1-5 m)$ & A. Pallares \\
\hline Bahía de Cartagena (Bol.) & 0,4 & $r, c$ & $\mathrm{Rm}$ & $\operatorname{tr}(1 \mathrm{~m})$ & A. Pallares \\
\hline Isla de Santa Catalina (SAP) & $?$ & $r$ & $\mathrm{Rm}$ & $\mathrm{pl}$ & M.C. Prada \\
\hline Tumaco (Nar.) & 1,5 & $\mathrm{t}$ & $\begin{array}{l}\mathrm{Ag}, \mathrm{Lr}, \mathrm{Rh} \\
\mathrm{Rm}, \mathrm{Rr}\end{array}$ & hi & $\begin{array}{l}\text { H. Rodríguez, S. } \\
\text { Salazar y C. Araujo }\end{array}$ \\
\hline Cartagena (Bol.) & $?$ & $c, r$ & $\mathrm{Ce}$ & $\begin{array}{l}\text { es, pl, tr } \\
(1-2 m)\end{array}$ & R. Alvarez-León \\
\hline Isla Arena (Bol.) & $?$ & e,c & $\mathrm{Ag}, \mathrm{Lr}, \mathrm{Pr}, \mathrm{Rm}$ & hi, pl, tr & L.G. Cano \\
\hline $\begin{array}{l}\text { Ciénaga de la Ahuyama } \\
\text { (Mag.) }\end{array}$ & 0,5 & $\mathrm{~h}$ & $\mathrm{Ag}, \mathrm{Lr}, \mathrm{Rm}$ & $\mathrm{pl}, \mathrm{tr}, \mathrm{rn}$ & $\begin{array}{l}\text { ECO- } \\
\text { DESARROLLO }\end{array}$ \\
\hline $\begin{array}{l}\text { Ciénaga Grande de Santa } \\
\text { Marta (Mag.) }\end{array}$ & $?$ & $\mathrm{t}, \mathrm{h}$ & $\mathrm{Ag}, \mathrm{Rm}$ & hi, pl & B.E. Giraldo \\
\hline $\begin{array}{l}\text { La Rinconada, Caño Grande } \\
\text { y La Aguja (Mag.) }\end{array}$ & 0,01 & $h, d$ & $\mathrm{Ag}, \mathrm{Lr}$ & $\mathrm{pl}$ & C. Elster \\
\hline Río Calancala (Gua.) & $?$ & $\mathrm{t}, \mathrm{c}$ & $\mathrm{Rm}$ & $\mathrm{pl}$ & CORPOGUAJIRA \\
\hline $\begin{array}{l}\text { Ciénaga de Tesca, Caño } \\
\text { Lequerica (Bol.) }\end{array}$ & $?$ & $t, c, r$ & $\mathrm{Rm}$ & $\mathrm{pl}$ & DAMARENA \\
\hline Isla Arena (Bol.) & $?$ & $\mathrm{e}$ & $\mathrm{Rm}$ & $\mathrm{pl}$ & R. Alvarez-León \\
\hline $\begin{array}{l}\text { Tumaco y Francisco Pizarro } \\
\text { (Nar.) }\end{array}$ & $?$ & $t, c, i$ & $\begin{array}{l}\mathrm{Ag}, \mathrm{Lr}, \mathrm{Mo} \\
\mathrm{Rh}, \mathrm{Rm}, \mathrm{Rr}\end{array}$ & hi, pr & $\begin{array}{l}\text { J.L. Freyre, } \\
\text { S. Salazar y } \\
\text { H. Rodríguez }\end{array}$ \\
\hline Cartagena (Bol.) & $?$ & 0 & $\mathrm{Ce}$ & $\begin{array}{l}\text { es, pl, tr } \\
(1-2 \mathrm{~m})\end{array}$ & R. Alvarez-León \\
\hline Puente de la Barra (Mag.) & $?$ & $h, r$ & $\mathrm{Ag}, \mathrm{Rm}$ & hi, pl & A.Celis \\
\hline $\begin{array}{l}\text { Veredas el Pital y Boca de } \\
\text { Brazo, Río Cajambre (Valle) }\end{array}$ & $?$ & $t, c, i$ & Mo & $\mathrm{pr}, \mathrm{pl}, \mathrm{fe}$ & A.Cabrera \\
\hline $\begin{array}{l}\text { Isla de San Martín de } \\
\text { Pajarales (Bol.) }\end{array}$ & $?$ & $e, c$ & $\mathrm{Rm}$ & hi & C.A. Bohórquez \\
\hline $\begin{array}{l}\text { Pasacaballos y Ciénaga de } \\
\text { la Virgen (Bol.) }\end{array}$ & $?$ & $d, r$ & $\mathrm{Rm}$ & hi, pl & DAMARENA \\
\hline
\end{tabular}




$\begin{array}{llll}\mathrm{Ag}: & \text { Avicennia germinans } & \mathrm{pl} & \text { plántulas } \\ \mathrm{Ce} & \text { Conocarpus erectus } & \mathrm{pr} & \text { propágulos } \\ \mathrm{Lr} & \text { Laguncularia racemosa } & \mathrm{tr} & \text { transplante } \\ \mathrm{M} & \text { Mora oleifera } & \mathrm{rn} & \text { regeneración natural } \\ \mathrm{Rh} & \text { Rhizophora harrisoni } & \mathrm{c} & \text { construcción } \\ \mathrm{Rm} & \text { R. Mangle } & \mathrm{d} & \text { dragado } \\ \mathrm{Rr} & \text { R. Racemosa } & \mathrm{e} & \text { erosión } \\ \mathrm{es} & \text { esqueje } & \mathrm{h} & \text { hipersalinización } \\ \mathrm{hi} & \text { hipocótilos } & \mathrm{i} & \text { inundación } \\ \mathrm{It} & \text { latizos } & \mathrm{o} & \text { ornamentación } \\ \mathrm{fe} & \text { fajas de enriquecimiento } & \mathrm{q} & \text { quema } \\ & & \mathrm{r} & \text { relleno }\end{array}$

$\begin{array}{ll}\mathrm{t} & \text { tala } \\ \text { Cor. } & \text { Depto. de Córdoba } \\ \text { Bol. } & \text { Depto. de Bolívar } \\ \text { Gua. } & \text { Depto. de la Guajira } \\ \text { Mag. } & \text { Depto. del Magdalena } \\ \text { Nar. } & \text { Depto. de Nariño } \\ \text { SAP } & \text { Depto. de San Andrés, } \\ & \begin{array}{l}\text { Providencia y Santa } \\ \text { Catalina }\end{array} \\ ? & \text { sin datos del área utilizada. }\end{array}$
Se construyeron con madera, malla plástica de encierro y malla polisombra, instalándose mesones en dos niveles. Su construcción se efectuó cerca de los esteros para facilitar las labores de riego y trasplante (Guevara-Mancera, 1998; Guevara-Mancera et al., 1998).

\section{Seguimiento de las características} físico-químicas de las aguas del manglar. Resumiendo los resultados del registro continuo de los parámetros físicoquímicos de las aguas de los manglares en el Caribe de Colombia, en 19 estaciones de registro correspondientes a lugares dentro de las parcelas permanentes de crecimiento y de restauración, se destaca que: en algunas de las aguas internas o de inundación, se observó una tendencia al calentamiento, con extremos de $40,0^{\circ} \mathrm{C}$ en el caño Dago, Bahía de Cispatá y de $41,0{ }^{\circ} \mathrm{C}$ en el Garzal en la Ciénaga de la Caimanera. Esta tendencia se debe a deficiencias en el flujo hídrico y sobreexposición a los rayos lumínicos por carencia de vegetación. Mientras que, en aguas internas de las mayorías de las estaciones, con máximos de $38,0{ }^{\circ} \mathrm{C}$, promedios de $29,8 \stackrel{\circ}{ }$ - y mínimos de 25,0 ${ }^{\circ} \mathrm{C}$, se presentan condiciones más favorables y con niveles no críticos a lo largo del periodo de muestreos. Los niveles de $\mathrm{pH}$ indican un comportamiento normal, oscilando entre 6,5 y 8,5 unidades. La concentraciones de sales en las aguas de los manglares están en un intervalo entre 0 y 88 unidades prácticas de salinidad (ups), según las características de los diferentes lugares, con evidencia de incrementos importantes en la época de sequía y disminuciones en temporadas Iluviosas. Existen niveles de salinidad con tendencia a ser críticos para el desarrollo de los manglares como es el caso de los registros efectuados en las estaciones del Garzal, en la Ciénaga la Caimanera, Sucre; Balsillas, Sucre, Caño Dago en la Ciénaga de Cispatá y Ciénaga de Balboa en el Atlántico (Pino-Rengifo, 1998; Sánchez-Páez, 1998).

En la costa Pacífica se instaló una red de monitoreo de aguas de 16 estaciones ubicadas en los cuatro Departamentos: el agua intersticial en los bosques de manglar del Pacífico presenta variaciones para los parámetros medidos, entre la marea baja y alta, según la estación y de acuerdo con la influencia del mar o de los ríos. Así por ejemplo, la salinidad puede variar en algunos casos desde 2 ups hasta 30 ups alcanzando valores promedios de $9 \mathrm{ppm}$ y $26,2 \mathrm{ppm}$ y el oxígeno desde $5,3 \mathrm{mg} / \mathrm{litro}$ a 7,7 $\mathrm{mg} /$ litro. Durante la marea alta los valores de los parámetros medidos son los más elevados. Respecto a la temperatura y al $\mathrm{pH}$, presentan en general variaciones mucho menores, tanto en estaciones como entre los tres niveles de marea considerados. Las aguas superficiales presentaron la mayor diferencia de promedios equivalente a $1,8 \stackrel{\circ}{\mathrm{C}}(28,5 \circ \mathrm{O}$ 29,3 으). Bajo estos parámetros, los manglares del Pacífico se hallan en un nivel adecuado para su desarrollo (Guevara-Mancera y Pinto-Nolla, 1998; Sánchez-Páez, 1998). 


\section{CONCLUSIONES}

- Como resultado de las investigaciones realizadas hasta la fecha, se ha logrado obtener valiosa información sobre el uso y manejo de hipocótilos, plántulas y plantas de Rhizophora mangle en la recuperación de áreas intervenidas y susceptible de ser manejadas silviculturalmente.

- Las experiencias obtenidas con Laguncularia racemosa y Avicennia germinans permiten tener bases para emprender nuevas acciones en áreas muy concretas, en las cuales desempeñan un papel fundamental, producto de la dinámica sucesional 0 a las alteraciones antropogénicas.

- La experiencia que tradicionalmente se tiene de la utilización de Conocarpus erectus, permite disponer de una especie bastante resistente a las alteraciones ambientales y de gran aceptación ornamental y silvicultural.

- Serán indispensables nuevas investigaciones para tener un conocimiento integral del comportamiento de las especies de manglar, incluidas Mora oleifera y Pelliciera rhizophorae, en su ambiente natural. Este conocimiento y las medidas gubernamentales de protección, garantizarán el correcto manejo sustentable de estos valiosos ecosistemas.

- Hasta el momento los esfuerzos realizados han sido aislados e intermitentes, a excepción del Proyecto Nacional de Manglares MMA/OIMT, por lo que deberán aprovecharse las experiencias obtenidas, sintetizar y analizar sus resultados y darles una amplia difusión dentro del Programa Nacional de Manglares (Sánchez-Páez et al., 2000; MMA, 2002).

- Tener la decisión política a nivel gubernamental que asegure la continuidad de los esfuerzos locales, regionales y nacionales en los aspectos de investigación y administrativos.

- Implantar un sistema de seguimiento y registro continuo, permanente y actualizado, con amplia difusión nacional sobre los resultados obtenidos en los diferentes ecosistemas de manglar.

- Es fundamental que en cualquier práctica silvicultural de los manglares colombianos se tengan en cuenta las características específicas de los bosques tropicales húmedos y de los bosques tropicales secos, zonas dentro de las cuales se sitúan estos ecosistemas en Colombia, así como las propias del entorno, para garantizar la producción sustentable del bosque natural y permitir un aprovechamiento igualmente sustentable y unas prácticas silviculturales apropiadas (De Las Salas, 1987; Lamprecht, 1990).

\section{RECONOCIMIENTOS}

A todas las personas e instituciones que han colaborado en la protección y recuperación de las áreas de manglar que han sufrido deterioro a diferente nivel, en las costas colombianas

\section{REFERENCIAS}

Alvarez-León, R. 1979. Bibliografía sobre la Bahía de Cartagena y sus alrededores hasta septiembre de 1979. UBJTL - Inf. Museo del Mar, 24: 1-26.

Alvarez-León, R. 1980. Bibliografía sobre la Ciénaga Grande de Santa Marta, la Isla de Salamanca y sus áreas de influencia, hasta mayo de 1980. INDERENA - Sugerencia de Pesca y Fauna. Bogotá D.E. Inf. Técnico 1:1-25.

Alvarez-León, R. 1992. Sinopsis sobre el conocimiento de los ecosistemas de manglar en Colombia: Segunda 
Revisión. Workshop on Conservation and Sustainabable Utilization of the Mangrove Forest in Latin America and Africa Regions. ITTO/ISME/UFF. Niterói (R.J.) Brasil. May 28-30. 53 p.

Alvarez-León, R. 1993. Mangrove ecosystems of Colombia. In: Lacerda, L.D. (ed.) Conservation and sustainable utilization of mangrove forest in Latin América and Africa Region. IITO/ISME Proj. PD 114/90 (F) Mangrove Ecosystems Technical Reports. Vol. 2. p:75-113.

Alvarez-León, R. 1997. Bibliografía sobre el conocimiento de los ecosistemas de manglar en Colombia. Proy. PD 171/91 Rev. 2 (F) Fase I. Conservación y Manejo para el Uso Múltiple y el Desarrollo de los Manglares en Colombia, MINAMBIENTE/OIMT. Santa Fe de Bogotá D.C., Colombia. Inf. Técnico 9:1-169

Arango-Estévez, X. 2001. Repoblamiento experimental de manglar en sectores adyacentes al Canal Clarín, Delta Exterior del Río Magdalena. Tesis Profesional. Fac. Biol. Marina. Univ. de Bogotá Jorge Tadeo Lozano. 110 p.

Autry, A.S.; V. Stewart; M. Fox y W. Hamilton. 1973. Progress report: mangrove planting for stabilization of developing shoreline. Q. J. Fla. Acad. Sci. 36 (Suppl. 1). 17p.

Avendaño-Remolina, D. y L.E. SánchezArias. 1993. Recuperación de un suelo de manglar afectado por hidrocarburos en litorales de Cartagena. UBJTL/ECOPETROL/ICP. Cartagena (Bol.). Inf. Técnico: 1-20

Avendaño-Remolina, D. y L.E. SánchezArias. 1995. Desarrollo y valoración de una técnica de recuperación de un suelo de manglar afectado por hidrocarburos en predios de ECOPETROL-Cartagena. Tesis Profesional.
Fac. Biol. Marina. Univ. de Bogotá Jorge Tadeo Lozano.124 p.

Bascope, F.A.; L. Bernardi; R.N Jorgensen; K. Hueck; H. Lamprecht y P. Martínez. 1959. Los manglares de América. Bol. Inst. Forest. Latinoamericano Invest. y Capac. Mérida, Venezuela. $62 \mathrm{p}$.

Bohórquez-Rueda, C.A. 1994. Transplantes de mangle rojo (Rhizophora mangle) a Cayo Ballena. Bol. CEINER 4:26-27.

Bohórquez-Rueda, C.A. 1996. Restoration of mangroves in Colombia: A case study of Rosario's Coral Reef National Park. Chap. 13 pp: 186-196 In: Colin, F. (ed.) Restoration of Mangrove Ecosystems. ITTO/ISME: Hong Kong, China. 250 p.

Bohórquez-Rueda, C.A. y M.C. PradaTriana. 1986. Siembra y transplante de Rhizophora mangle L. 1773 y tipología del manglar del Parque Nacional Corales del Rosario. Tesis Profesional. Fac. Biología Marina. Univ. de Bogotá Jorge Tadeo Lozano. 124 p.

Bohórquez-Rueda, C. A. \& M. C. PradaTriana. 1987. Siembra en vivero de propágulos de Rhizophora mangle L. 1883 en Isla Pavitos, Archipiélago de Nuestra Señora del Rosario. UBJTL Bol. Fac. Biol. Marina 7:3-7.

Bohórquez-Rueda, C.A. y M.C. PradaTriana. 1988. Transplante de plántulas de Rhizophora mangle (Rhizophoraceae) en el Parque Nacional Corales del Rosario, Colombia. Rev. Biol. Trop. 36 (2B):555-557.

Campos, E. 2001. Impacto de la herbivoría por parte de Junonia evarete en el reclutamiento de propágulos y el desarrollo de plántulas de Avicennia germinans y 
Laguncularia racemosa en la Ciénaga Grande de Santa Marta. Tesis Profesional. Fac. de Ciencias. Pontificia Univ. Javeriana. 130 p.

Cañón-Escobar, G.M. y H. RodríguezCruz. 1994. Ensayos de repoblamiento con Rhizophora mangle L. en Isla Arena, Parque Nacional Corales del Rosario, Caribe Colombiano. Tesis Profesional. Fac. Biol. Marina, Univ. de Bogotá Jorge Tadeo Lozano. $123 \mathrm{p}$.

Carlton, J.M. 1974. Lund-building and stabilization by mangroves. Environmental Conservatinos 1(4):285-294.

Casas-Monroy, O. 1999. Patrones de regeneración natural del manglar en la Ciénaga Grande de Santa Marta, Caribe colombiano. Tesis Profesional. Fac. de Biol. Marina. Univ. de Bogotá Jorge Tadeo Lozano. 126 p.

Castañeda-Moya, E. 1998. Fenología reproductiva de Avicennia germinans y Rhizophora mangle en el Delta Exterior del Río Magdalena-Ciénaga Grande de Santa Marta, Caribe colombiano. Tesis Profesional. Fac. de Biol. Marina. Univ. de Bogotá Jorge Tadeo Lozano. 118 p.

Correa, S.B.; L.M. Granada y M.X. Zorrilla. 2002. Comunicación personal.

De Las Salas, G. 1987. Suelos y ecosistemas forestales, con énfasis en América Tropical. Serv. Edit. IICA. San José, Costa Rica. Col. Libros y Materiales Educativos 89. 450 p.

Del Valle-Arango, J.I. 1996. Los bosques de guandal del delta del río Patía (Colombia). Rev. Acad. Colomb. Cienc. (78):475-489.

Egler, F.E. 1948. The dispersal and establishment of mangrove, Rhizophora in Florida. Caribb. Forest. 9(4):299-310.
Elster, C. 1997. Beziehung zwischen öekologischen Faktoren und der Regeneration dreier Mangrovenarten im Gebiet der Cienaga Grande de Santa Marta, Kolumbien. These Doktorwürde. Justus-Liebig Univ. Giessen. 221 p.

Elster, C. 1998a. Regenerationsmoglichkeiten der Mangrove im Gebiet der Cienaga Grande de Santa Marta (Kolumbien). Okologie Tropicher Waldsysteme. Deutsche Geesellschaft fur Technische Zusammenarbeit (GTZ) $\mathrm{GmbH}$. Eschborn, Alemania. 58 p.

Elster, C. 1998b. Posibilidades de regeneración del manglar en la zona de la Ciénaga Grande de Santa Marta, Colombia. Ecología de los Bosques Tropicales. Tropenokologisches Begleitprogramm (TOB)/Deutsche Geesellschaft fur Technische Zusammenarbeit (GTZ) GmbH. Eschborn, Alemania. 58 p.

Elster, C. 2000. Reasons for reforestation succes and failure with tree mangrove species in Colombia. Forest Ecology and Management 131:201-214.

Elster, C. 2001. Mangroven: Ihr Stellenwert Ursachen ihrer Schadigung Moglichkeiten inner Rehabilitierung. Deutsche Geesellschaft fur Technische Zusammenarbeit (GTZ) $\mathrm{GmbH}$. Eschborn, Alemania. 140 p.

Elster, C. y L. Perdomo-Trujillo. 1998. Rooting and vegetative propagation in Laguncularia racemosa. Aquatic Botany 63:83-93.

Elster, C. y M.L. Schnetter. 1998. Seedling development of mangrove species of the Caribbean coast of Colombia under controlled conditions. Mittlg. BFH 190:311-316. 
Elster, C. y J.H. Polanía-Vorenberg. 2000. Posibilidades de recuperación del manglar en la Ciénaga Grande de Santa Marta, Colombia. Actual. Biol. 22(72):29-36.

Elster, C.; L. Perdomo-Trujillo y M. L. Schnetter. 1996. Relaciones entre la tasa de sobrevivencia de plántulas voluntarias, transplantes y propágulos de tres especies de mangle y los factores ambientales en la Ciénaga Grande de Santa Marta, Colombia. X Sem. Nal. Cienc. y Tecnol. del Mar. CCO/COLCIENCIAS. Santa Fe de Bogotá D.C., Colombia. Resumen 1.18.

Elster, C.; J.H. Polanía-Vorenberg y O. Casas-Monroy. 1999a. Restoration of the Magdalena River Delta, Colombia. Vida Silvestre Neotropical 7(1): 23-29.

Elster, C.; L. Perdomo-Trujillo y M.L. Schnetter. 1999b. Impact of ecological factors on the regeneration of mangroves in the Ciénaga Grande de Santa Marta, Colombia. Hydrobiologica 413:35-46.

Ensminger, I. 1996. Hydrologische Veränderungen am Canal Clarín und ihre Bedeutung fúr die Regeneration salzgeschädigter Mangrove. Diplomabeit. Justus-Liebig Univ. Giessen. $137 \mathrm{p}$.

Falla-Ramírez, A. 1970. Definición de términos silviculturales. Proy. INDERENA/FAO/COL/14. Bogotá D.E. Boletín 3:1-27.

FAO (Organización de las Naciones Unidas para la Agricultura y la Alimentación). 1970. Investigación silvícola: Metodología para el establecimiento de parcelas experimentales. Proy. FAO/COL/14. Bogotá D.E. Boletín, 3: 1-27.
FAO (Organización de las Naciones Unidas para la Alimentación). 1996. Informe del Taller Internacional sobre Experiencias de Políticas de Incentivos para la Forestación en America Latina y el Caribe. Santiago de Chile, Chile. Diciembre 4-6 de 1995. FAO. Ser. Forest. 6: 1-39.

Gaviria-Flórez, J.E. y M.P. GonzálezPalacio. 1998. Incidencia de algunos factores ambientales en la distribución del bosque de manglar en la isla Grajales, Delta del Río San Juan (Pacífico colombiano). Tesis Profesional. Fac. Cienc. Agropecuarias. Univ. Nal. de Colombia. Sede Medellín. 167 p.

Giraldo, B. 1995. Estimación de la regeneración natural del manglar en la Ciénaga Grande de Santa Marta, Caribe colombiano. Tesis Profesional. Fac. de Ciencias. Univ. del Valle. $142 \mathrm{p}$.

González-Calderón, D. y B. RivasEcheverri. 1993a. Obtención de plántulas viables para la siembra por estimulación de raíces adventicias en Rhizophora mangle L. 1773, aplicando la técnica de acodado área. UBJTL Fac. Biol. Marina. Cartagena (Bol.). Inf. Técnico: 1-12.

González-Calderón, D. y B. RivasEcheverri. 1993b. Transplante de plántulas del medio natural y siembra de acodos de Rhizophora mangle L. 1773, en tres zonas del Archipiélago de Nuestra Señora del Rosario, Caribe colombiano. Tesis Profesional. Fac. de Biología Marina. Univ. de Bogotá Jorge Tadeo Lozano. 114 p.

Grosso-Vargas, J.L.; L.E. Sánchez-Arias; D. Avendaño-Remolina y R. Restrepo. 1995a. Control de salinidad en efluentes líquidos en campos de producción de petróleo mediante la utilización de manglares. Fase I. ICP- 
ECOPETROL/BIOSFERA. Barrancabermeja (Sant.). Inf. Técnico: 1-52.

Grosso-Vargas, J.L.; L.E. Sánchez-Arias; R. Restrepo y D. AvendañoRemolina. 1995b. Control de salinidad en efluentes líquidos en campos de producción de petróleo mediante la utilización de manglares (Rhizophora mangle, Laguncularia racemosa, Avicennia germinas). ICPECOPETROL/BIOSFERA/FEN-

Colombia. Santa Fe de Bogotá D.C. Inf. Técnico: 1-54.

Grosso-Vargas, J.L.; R. Restrepo; L.E. Sánchez-Arias; D. Avendaño-Remolina e I. Mantilla. 1996a. Evaluación preliminar de la participación de especies de mangle en el control de metales pesados en aguas de producción. ECOPETROL/ICP, CT\&F Ciencia, Tecnología y Futuro 1(2):55-65.

Grosso-Vargas, J.L.; R. Restrepo; L.E. Sánchez-Arias; D. Avendaño-Remolina e I. Mantilla. 1996b. Evaluación de las especies de manglar como alternativa de tratamiento de metales pesados y salinidad en efluentes industriales de la producción petrolera. Mem. Resúmenes y Trabajos 2nd. Internal. Symp. Envirn. Geoch. In Tropical Countries, INGEOMINAS/IDEAM/UFF. Cartagena (Bol.) Colombia. nov.18-21.

Guevara-Mancera, O.A. 1998. Manual para la restauración de los bosques de manglar en áreas degradadas del Pacífico colombiano. Proyecto PD 171/91 Rev. 2 Fase II (Etapa 1) Conservación y Manejo para el Uso Multiple y el Desarrollo de los Manglares en Colombia, MMA/ ACOFORE/OIMT, Santa Fe de Bogotá D.C., Colombia. 16 p.

Guevara-Mancera, O.A. y F. Pinto-Nolla. 1998. Monitoreo y caracterización de aguas de los manglares del Pacífico colombiano. PD 171/91 Rev. 2 Fase II (Etapa I) Conservación y Manejo para el Uso Múltiple de los Manglares de Colombia, MINAMBIENTE/ ACOFORE/OIMT. Santa Fe de Bogotá D.C., Colombia. Inf. Técnico 27:1-37.

Guevara-Mancera, O.A.; H. SánchezPáez; G.O. Murcia-Orjuela; H.E. Bravo-Pazmiño; F. Pinto-Nolla y R. Alvarez-León. 1998. Conservación y uso sostenible de los manglares del Pacífico colombiano. In: SánchezPáez, H.; O.A. Guevara-Mancera y R. Alvarez-León (eds.) Proy. PD 171/91 Rev. 2 Fase II (Etapa I) Conservación y Manejo para el Uso Múltiple y el Desarrollo de los Manglares de Colombia, MINAMBIENTE/ ACOFORE/OIMT. Santa Fe de Bogotá D.C., Colombia. 178 p.

Hernández-Camacho, J.I.; H. SánchezPáez; R. Alvarez-León y R. Echeverri. 1978a. Concepto sobre el permiso clase B del aprovechamiento del mangle a Quintal S.A. Gerencia General INDERENA. Bogotá D.E., Colombia. Inf. Técnico 1. 3 p.

Hernández-Camacho, J.I.; R. AlvarezLeón; R. Echeverri; P. von Hildebrand; H. Sánchez-Páez; L. Gutiérrez; P. Andrade y L. Tibaquirá. 1978b. Concepto sobre la explotación industrial del las especies de mangle en el país. INDERENAGerencia General, Bogotá D.E., Colombia. Inf. Técnico 2. 25 p.

Ibáñez-Granados, M. 1992a. Experiencias de ECOPETROL - Cartagena en recuperación de ecosistemas de manglar contaminados por derrames de hidrocarburos. ECOPETROL Distrito Refinería de Cartagena. Cartagena (Bol.). Inf. Técnico: 1-28.

Ibáñez-Granados, M. 1992b. Experiencias de ECOPETROL - Cartagena en recuperación de ecosistemas de 
manglar contaminados por derrames de hidrocarburos. In: Mem. V Congr. Colomb. del Petróleo. Santa Fe de Bogotá D.C., Colombia. Oct. 13-16. Tomo II. p:238-258.

Ibáñez-Granados, M. 1995. Mangrove restoration: Cartagena, Colombia, coastal oil spill case study, In: Oil Spill Conference Poster Session W3. Sweden. p:990-991.

IGAC. 1966. Mapa de Bosques de Colombia. Memoria Explicativa y Mapas. Inst. Geogr. Agustín Codazzi. Bogotá D.E., Colombia.

INDERENA. 1991. Diagnóstico explotatorio de los manglares en Colombia. Inst. Nal. Rec. Nat. Renov. $y$ el Ambiente/Subgerencia de Bosques y Aguas. Santa $\mathrm{Fe}$ de Bogotá D.C. Inf. Técnico: 1-43.

INDERENA/IGAC/CONIF. 1984. Mapa de Bosques de Colombia. Memoria Explicativa y mapas. Inst. Nal. Rec. Nat. Renov. y Ambiente/Inst. Geogr. Agustín Codazzi/Com. Nal. Inv. Forest. Bogotá D.E., Colombia.

Jiménez-Cárdenas, A.V. y J. BecerraRodríguez. 1987. Siembra de plantas e hipocótilos de Rhizophora mangle L. a nivel experimental en un área del Parque Zona Atlántico Corales del Rosario. Fac. Biol. Marina. Univ. de Bogotá Jorge Tadeo Lozano. Cartagena (Bol.). Inf. Técnico: 1-45.

Lamprecht, H. 1990. Silvicultura en los trópicos: los ecosistemas forestales en los bosques tropicales y sus especies arbóreas: posibilidades y métodos para un aprovechamiento sostenido. Deutsche Geesellschaft fur Technische Zusammenarbeit (GTZ). A. Carrillo (trad.). Rossdorf, Alemania. $335 \mathrm{p}$.

Marín-Restrepo, J. H. 1998. Análisis preliminar de la regeneración natural y de los suelos del manglar en la Isla Grajales, Delta del Río San Juan (Pacífico colombiano). Tesis Profesional. Fac. Cienc. Agropecuarias. Univ. Nal. de Colombia. Sede Medellín. 126 p.

Mendoza-Forero, C. 2000. Acción de las poliaminas sobre el crecimiento lento de las plántulas de Rhizophora mangle. Tesis Profesional. Fac. Cienc. Univ. Nal. de Colombia.

Mendoza-Forero, C.; H.M. Moreno y J.H. Polanía-Vorenberg. 2002. Mecanismos hormonales mediados por poliaminas en la etapa de crecimiento lento en plántulas del mangle rojo (Rhizophora mangle. L.). In: Rangel, J.O.; J. Aguirre y M.G. Andrade (eds.) Mem. Resúmenes VIII Congr. Latinoamericano y II Colombiano de Botánica. INCUNC/ALB/ACB/RLB/MMA MBG FNC IIBAvH/FPAA/ACH/ACCE/Alianza

Summa/Staedtler. Cartagena (Bol.), Colombia. Octubre 13-18. p. 100.

Moreno-Bejarano, L.M. 1984. Variación en la vegetación del Parque Nacional Isla de Salamanca. INDERENA-Div. Parque Nacional y Vida Silvestre/ Regional Atlántico. Barranquilla (Atl.). Informe Técnico:1-55.

Moreno-Bejarano, L.M. 2002. Comunicación personal

Neyra-Román, M. 1981. Investigación y desarrollo forestal: Colombia. Proy. Silvicultura INDERENA/PNUD/FAO/ CONIF- Col/74/005. Roma, Italia. Doc. de Trabajo. $222 \mathrm{p}$.

MMA. 2002. Programa sobre el uso sostenible, manejo y conservación de los ecosistemas de manglar. Min del Medio Ambiente. Santa Fe de Bogotá D.C., Colombia. 59 p.

Pallares, A. 2002. Comunicación personal. 
Perdomo-Trujillo, L.V. 1996. Siembra y transplante de plántulas de mangle en el área de la Ciénaga Grande de Santa Marta, Colombia. Tesis Profesional. Fac. Biol. Marina. Univ. de Bogotá Jorge Tadeo Lozano. 72 p.

Perdomo-Trujillo, L.V. 2001. Evaluación de procesos de regeneración natural del manglar después de la reapertura de los caños de agua dulce (Ciénaga Grande de Santa Marta, Colombia). Tesis de M. Sc. Fac. de Ciencias. Univ. Nal. de Colombia. 107 p.

Perdomo-Trujillo, L.V.; I. Ensminger; L.F. Espinosa; C. Elster; M. WalnnerKersanach y M.L. Schnetter. 1999. The mangrove ecosystem of the Ciénaga Grande de Santa Marta (Colombia): Observations on regeneration and trace metals in sediment. Mar. Poll. Bull. 37(812):393-403.

Pino-Renjifo, J.C. 1998. Monitoreo en aguas de los manglares del Caribe continental colombiano. Proy. PD 171/91 Rev. 2 Fase II (Etapa I) Conservación y Manejo para el Uso Múltiple y el Desarrollo de los Manglares de Colombia, MINAMBIENTE/ ACOFORE/OIMT. Santa $\mathrm{Fe}$ de Bogotá D.C., Colombia. Inf. Técnico 26:1-98.

Pulver, T.R. 1976. Trasplanting techniques for sampling mangrove trees, Rhizophora mangle, Laguncularia racemosa and Avicennia germinans in Florida, Fla. Dept. Nat. Resour. Fla. Mar. Res. Publ. 22:1-15.

Rabinowitz, D. 1974. Planting experiments in mangrove swamps of Panamá, In: Walsh, G.; S. Snedaker y H. Teas (eds.). Proc. Internal. Symip. Biology and Management of Mangroves. East Center, Honolulu, Hawaii. October 8-11. Vol. I. p:385-393.
Rodríguez-Cruz, H. 1998. Restauración de las áreas de manglar en el Caribe continental de Colombia. Proy. Conservación y Manejo para el Uso Múltiple y el Desarrollo de los Manglares de Colombia. PD 171/91 Rev. 2 (F). Santa Fe de Bogotá D.C. Inf. Técnico 20:1-38.

Rodríguez-Cruz, H. 2002. Comunicación personal.

Rodríguez-Gómez, H. 2002. Comunicación personal.

Sánchez-Arias, L.E.; D. AvendañoRemolina; R. Alvarez-León y J.L. Grosso. 1996. Development and evaluation of a recuperation technique about mangrove's soils affected with hydrocarbons. Mem. Resúmenes y Trabajos 2nd. Internal. Symp. Envirn. Geoch. in Tropical Countries, INGEOMINAS/IDEAM/UFF. Cartagena (Bol.), Colombia. Nov. 18-21. p. 127.

Sánchez-Páez, H. 1988. Hacia la salvación del Parque Nacional Natural Isla de Salamanca. Trianea Act. Cient. Tecn. INDERENA 2:505-527.

Sánchez-Páez, H. 1998. Proyecto: Conservación y manejo para el uso múltiple y el desarrollo de los manglares de Colombia. PD 171/91 Rev. 2 (F). UDFJC-Colombia Forestal 5(11):41-55.

Sánchez-Páez, H. y G.A. Ulloa-Delgado. 2000. Experiencias de restauración en el Proyecto Manglares de Colombia. In: Ponce de León, E. (ed.) Mem. Sem. Sem. Nal. de Restauración Ecológica y Reforestación. FAAE/FFEC/FESCOL/FNA/GTZ. Dic. 2 y 3 de 1999. Santa Fe de Bogotá D.C., Colombia. p:219-258.

Sánchez-Páez, H.; R. Alvarez-León; O.A. Guevara-Mancera y G.A. UlloaDelgado. 2000. Lineamientos estra- 
tégicos para la conservación y uso sostenible de los manglares de Colombia. Proy. PD 171/91 Rev. 2 (F) Fase II (Etapa II). Conservación y Manejo para el Uso Múltiple y el Desarrollo de los Manglares de Colombia. MINAMBIENTE/OIMT. Santa Fe de Bogotá D.C., Colombia. $81 \mathrm{p}$.

Sánchez-Páez, H.; R. Alvarez-León; F. Pinto-Nolla; A.S. Sánchez-Alferez; J.C. Pino-Renjifo; I. Garcia-Hansen y M.T. Acosta-Peñaloza. 1997a. Diagnóstico y zonificación preliminar de los manglares del Caribe de Colombia. In: Sánchez-Páez, H. y R. Alvarez-León (eds.) Proy. PD 171/91 Rev. 2 (F) Fase I. Conservación y Manejo para el Uso Múltiple y el Desarrollo de los Manglares de Colombia. MINAMBIENTE/OIMT. Santa Fe de Bogotá D.C., Colombia. $511 \mathrm{p}$.

Sánchez-Páez, H.; R. Alvarez-León; O.A. Guevara-Mancera; A. ZamoraGuzmán; H. Rodríguez-Cruz y H.E. Bravo-Pazmiño. 1997b. Diagnóstico y zonificación preliminar de los manglares del Pacífico de Colombia. In: Sánchez-Páez, H. y R. AlvarezLeón (eds.) Proy. PD 171/91 Rev. 2 (F) Fase I. Conservación y Manejo para el Uso Múltiple y el Desarrollo de los Manglares de Colombia. MINAMBIENTE/OIMT. Santa Fe de Bogotá D.C., Colombia. 343 p.

Sánchez-Páez, H.; G.A. Ulloa-Delgado; R. Alvarez-León; W.O. Gil-Torres; A.S. Sánchez-Alférez; O.A. GuevaraMancera; L.P. Callejas y F.E. PáezParra. 2000. Hacia la recuperación de los manglares del Caribe de Colombia. In: Sánchez-Páez, H.; G.A. Ulloa-Delgado y R. AlvarezLeón (eds.) Proy. PD 171/91 Rev. 2 (F) Fase II (Etapa II). Conservación y Manejo para el Uso Múltiple y el Desarrollo de los Manglares de Colombia. MINAMBIENTE/OIMT.
Santa Fe de Bogotá D.C., Colombia. 294 p.

Savage, T. 1972. Florida mangroves as shoreline stabilizers. Fla. Dep. Nat. Resour., Mar. Res. Lab., Prof. Pap. Ser. (19):1-46.

Serna-Terán, A. 1998. Ensayos sobre el almacenaje de embriones de Avicennia germinans, Laguncularia racemosa y Rhizophora mangle, empleando una técnica de almacenamiento para semillas recalcitrantes. Tesis Profesional. Fac. Biol. Marina. Univ. de Bogotá Jorge Tadeo Lozano. $112 \mathrm{p}$.

Silva, L.J. 1987. La investigación silvicultural en el bosque húmedo tropical en Colombia, pp:36-53 In: Solano, R. (ed.) Mem. Reu. Nal. de Silvicultura: Impacto de la Investigación Silvicultural Tropical en el Desarrollo Económico Forestal Colombiano. Bogotá D.E., Colombia. Abril 7-10. CONIF-Ser. Doc. 318 p.

Schnetter, M.L. 1969. Observaciones ecológicas sobre la Isla de Salamanca, Colombia. Caldasia 10(48):299-315.

Schnetter, M.L. 1978. Der. Einfluss von Aussefaktoren auf die Strucktur deer Blattes von Avicennia germinans (L.) L., unter naturlichen Bedigungen. Beitr. Biol. Pflanzen 54:13-28.

Schnetter, M.L. 1985. Untersuchungen Zur Salzansscheridung durch die Blatter bei Avicennia germinans (L.) L. Flora 177:157-165.

Schnetter, M.L. 1986. La influencia del pH y la salinidad en el crecimiento de Avicennia germinans, en el cultivo hidropónico. Caldasia 15(71-75): 381-391.

Schnetter, M.L. 2002. El sistema radical del mangle blanco (Avicennia 
germinans), un ejemplo de adaptaciones morfológicas y anatómicas en espermatófitos a condiciones ecológicas diversas. Rev. Acad. Colomb. Cienc. 26(98): 111-126.

Schubert, P. 1998. Verbreitung der Diasporen der Mangrovearten im Gebiet der Ciénaga Grande de Santa Marta/Kolumbien. Okologie Tropischer Waldsysteme. Tropenokologisches Begleitprogramm (TOB)/Deutsche Geesellschaft fur Technische Zusammenarbeit (GTZ) GmbH. Eschborn, Alemania. 52 p.

Thorhaug, A. s.f. Restoration of mangroves and seagrasses and attendant economic benefits for fisheries and mariculture; manaement, policy and planning. Draft Report. $6 \mathrm{p}$.

Ulloa-Delgado, G.A.; W.O. Gil-Torres; J.C. Pino-Rengifo y $\mathrm{H}$. Rodríguez-Cruz. 1998a. Manual sobre técnicas de vivero y restauración de áreas de manglar del Caribe colombiano. Proyecto PD 171/91 Rev. 2 Fase II (Etapa I) Conservación y Manejo para el Uso Multiple y el Desarrollo de los Manglares en Colombia, MMA/ACOFORE/OIMT. Santa Fe de Bogotá D.C., Colombia. 24 p.

Ulloa-Delgado, G.A.; H. Sánchez-Páez; W.O. Gil-Torres; J.C. Pino-Rengifo; $H$. Rodríguez-Cruz y R. AlvarezLeón. 1998b. Conservación y uso sostenible de los manglares del Caribe colombiano. In: UlloaDelgado, G.A.; H. Sánchez-Páez y R. Alvarez-León (eds.). Proyecto PD 171/91 Rev. 2 Fase II (Etapa I) Conservación y Manejo para el Uso Multiple y el Desarrollo de los Manglares en Colombia, MMA/ ACOFORE/OIMT. Santa Fe de Bogotá D.C., Colombia. 224 p.

Vélez-Escobar, F. 1990. Conservación y aprovechamiento del bosque de manglar en la zona del Antiguo Delta del Río Sinú: Anotaciones sobre el Plan de Manejo Forestal del Bosque de Manglar. CVS/FVE. Medellín (Ant.). Inf. Técnico (1) $16 \mathrm{p}$.

Vélez-Escobar, F. 1991. Manejo silvicultural del bosque de manglar en la zona del Antiguo Delta del Río Sinú: Establecimiento de parcelas permanentes para el estudio de crecimiento. CVS/FVE. Medellín (Ant.). Inf. Técnico (2). 8 p.

Vélez-Escobar, F. 1993. Estudio de crecimiento del bosque de manglar en la zona del Antiguo Delta del Río Sinú. CVS/FVE. Medellín (Ant.). Inf. Técnico (3). $13 \mathrm{p}$.

Vélez-Escobar, F. 1994. Manejo silvicultural del bosque de manglar en la zona del Antiguo Delta del Río Sinú: Ecuaciones y tablas de volumen de tres especies de mangle. CVS/FVE. Medellín (Ant.). Inf. Técnico (4) 19 p.

Yanine-Díaz, D. 1991. Aspectos generales sobre uso, conservación y manejo de manglares en Colombia. INDERENA - Subgerencia de Bosques y Aguas. Santa Fe de Bogotá D.C., Colombia. Inf. Técnico. 26 p.

Zambrano-Escamilla, C.H. y D.J. RubianoRubiano. 1996. Memoria de los mapas de los bosques de manglar del Pacífico colombiano: 1969, 1996 y multitemporal. Proy. PD 171/91 Rev. 2 (F) Fase I. Conservación y Manejo para el Uso Múltiple y el Desarrollo de los Manglares en Colombia. MINAMBIENTE/OIMT. Santa Fe de Bogotá D.C., Colombia. Inf. Técnico 8:1-41.

Zambrano-Escamilla, C.H. y D.J. RubianoRubiano. 1997. Memoria de los mapas de los bosques de manglar del Caribe colombiano: 1996. Proy. PD 171/91 Rev. 2 (F) Fase I. Conservación y Manejo para el Uso Múltiple y el Desarrollo de los 
Manglares en Colombia, MINAM-

BIENTE/OIMT. Santa Fe de Bogotá

D.C., Colombia. Inf. Técnico 11:1-22.

1 Conservación Internacional-Colombia. Apdo. Aéreo 101372. Santa Fe de Bogotá D. C. Colombia. c.e.: alvarez_leon@hotmail.com.

Manuscrito recibido el 22 de octubre de 2002.

Aceptado el 29 de enero de 2003.

Este documento se debe citar como:

Álvarez-León, R. 2003. Los manglares de Colombia y la recuperación de sus áreas degradadas: revisión bibliográfica y nuevas experiencias. Madera y Bosques 9(1):3-25. 
